\title{
Unpacking FIFA play as text and action in literacy practices in and out of school
}

Abstract:

In the current article, we use a model for games and literacy to understand how one FIFA gamer worked across contexts with game literacy. Previously, the use of this model has been used within discussions revolving around computer and video games from the point of view of English and literacy curriculum and teaching. The analysis in this article expands on these previous views by using a learning lives perspective, which builds on the idea of following the learner across a wide range of contexts. The knowledge of the game and its culture and the world around the game is scrutinized by following one specific gamer of FIFA across diverse literacy practices in and out of school. The findings illustrate how learners perform their knowledge as they research a specific topic, building a convincing argument for it, and transferring knowledge from one source to another in a critical way.

\section{Introduction}

It is Friday night, and a gang of five boys (referred to as the FIFA-gang hereafter) are carrying big TV screens as they walk from one house to another on an island in South-eastern Norway. There is a buzzling of activity in the living room when they connect the screens with other devices, namely, their PlayStation 4s. Somehow, they manage to use different furniture in the living room to organise the three big TV sets beside each other. The scene is set for a long night of tournament play in the sports game FIFA. 
For over nearly three years, we followed the FIFA-gang and watched their deep engagement with the sports video game FIFA. In the interviews we conducted with them, they talked about the long nights of gaming, and eventually, we were able to video-record at least one of their social evenings. When reviewing these videos, two episodes became particularly interesting. To start this essay on the FIFA-gang's experiences in play and how this may translate into literacy practices, we show two excerpts that might introduce the aim of the current article:

\section{Excerpt 1:}

Boy 1: I can't shoot overhead kick when running. Do you hold down [button] R or...

Boy 2: $\quad$ R... [confirming tone]

Boy 3: $\quad$ hold down R2

Boy 4: $\quad$ And at the same time...

Boy 1: $\quad$ You run, while holding R2, right? ... before it was the 'running button', right?

For most who have played the FIFA video game, the first scene is familiar. One of the lessexperienced gamers is advised how to play the game (Gee, 2003, 2007). The excerpt illustrates how gamers are contributing to the creation of the game by using the game console and how these choices are learnt in the social context of gameplay. Thinking about this episode as a literacy practice, there is a specific game literacy which must be learnt to play FIFA. Excerpt 2 can be understood as a different kind of literacy related to the game:

\section{Excerpt 2:}

Boy 1: $\quad$ A long shot

Boy 2: $\quad$ He has double four

Boy 1: Why don't you use it?

Boy 2: He is bloody strong, he got 81 in 'acceleration' and 82 in 'positioning'.

Boy 1: He is bloody good!

Boy 2: $\quad$ Yes, he his bloody good, he's got (inaudible)

Boy 1: He is more 'beast' - he is more beast than last year. 
The second excerpt illustrates how the players discuss how one specific football player is 'programmed' in the game and how they talk about how this player has changed since the last version of the game. This episode demonstrates knowledge about the game and the world around the game by referring to the specific level on different skills in the avatar.

In the current article, we make use of a model for games and literacy (Beavis and Apperley, 2012) as a point of departure to understand the literacy practices related to the popular game FIFA. Previously, the use of this model has been related to discussions centring around computer and video games from the point of view of English and literacy curriculum and teaching (Apperley and Beavis, 2013; Beavis and Apperley, 2012), and it has been elaborated into a 3D model of literacy two decades ago (Green 1999). Originally, such a perspective intended to support the learning affordances offered by digital games to build bridges between students' out-of-school life-worlds and the school curriculum (Apperley and Beavis, 2013, 2). What we add to this perspective is a stronger emphasis on learners' agency by applying what we term a 'learning lives perspective'. This perspective builds on the idea of following the learner across contexts to understand how this learner may draw on resources in diverse literacy practices in different settings (Gilje and Erstad, 2014; Sefton-Green, 2016; SeftonGreen and Erstad, 2017). In the current article, we elaborate on how games-as-text can be understood as we analyse how one player builds upon his actions as a gamer of FIFA and transforms this knowledge into diverse literacy practices in the wider world. The following two interrelated questions guide the analysis:

- How do FIFA video game players participate in diverse literacy practices over time and across various contexts? 
- How do FIFA video game players make use of their knowledge about the game and the world around the game across contexts?

To answer these research questions, we draw on data from an ethnographic longitudinal project where the researchers studied students' learning and literacy practices in and out of school. The data used in the analysis consist of interviews, school assignments, 'mediographies' and video data from school projects and informal contexts, such as the snippets of the conversations above. In our work, we point toward a broader understanding of how humans learn and make meaning out of games beyond their social aspects. First, we provide some background information by drawing on previous and relevant studies and then present a theoretical framework for games and literacy. Second, we analyse how Emil, a member of the FIFA-gang, developed literacy across a wide range of contexts. Finally, we compare the different practices and discuss how these literacies can be utilised in schools, providing implications for teachers and recommended future research.

\section{Making sports games meaningful - research on the cultural and social context}

Over the last two decades, there has been an interest in how gamers - in the context of their everyday lives - position themselves in relation to their peers (Ito et al., 2009; Steinkuehler, 2006; Stevens, Satwicz, and McCarthy, 2008; Williamson and Facer, 2004) and how young people develop skills and knowledge in their gaming practices that occur in out-of-school settings (Hanghøj, Hautopp, Jessen, Denning, and Busch, 2014; Hayes, 2013; Leander and Jason, 2006; Steinkuehler and King, 2009), as well as in educational settings (Nash and Shaffer, 2011; Silseth, 2012; Øygardslia, 2018). This vast body of research has shown the complex social processes involved when young people make meaning of the content of games. More to the point here, some of these researchers have explored the ways in which 
games expand and rewrite conceptions of literacy as these games are co-created within the parameters of time and space (Beavis, Apperley, Bradford, O'Mara, and Walsh, 2009). Although, there is a growing number of studies addressing the literacies involved in playing sport games such as FIFA (Beavis et al., 2009; Del Castillo, Herrero, Monjelat, García, and Checa, 2011), these studies mainly have addressed learning and literacy in the classroom. Thus, it is interesting to understand more about how gamers play in their leisure time and how literacies in the game culture relate to other contexts.

Although the literature focusing on looking at sports games and their gamers in diverse social contexts is growing (Mitgutsch, 2011, 2013; Sicart, 2013; Stein, Mitgutsch and Consalvo, 2013), studies on how young people draw on their experience as gamers across contexts are rare. Thus, there is a need to look more into how sports games such as FIFA relate to a wide range of literacy practices and become meaningful across time and space (Leander, Phillips, and Taylor, 2010). This leaves us with an urgent question regarding how to theoretically understand what kind of literacy young people develop in their playing of sport games in general and FIFA in particular.

\section{Theoretical perspective}

Studies on literacies and gameplay reveal how digital games can be the sites of literacy learning (Beavis and O'Mara, 2010). Researchers have argued that games provide excellent examples of the ways in which literacy is reconfigured and redesigned in digital times and of the intersections between textual experience, meaning-making and the socially situated nature of play (Beavis and O'Mara, 2010, p. 88). Green (1988) proposed that we simultaneously think about literacy and technology in relation to three dimensions - cultural, critical and operational. Drawing on this 3D model as a way of thinking about subject-specific literacies 
(Green 1988, 1999), numerous researchers have sketched out a model for games and literacy (Apperley and Beavis, 2013; Beavis et al., 2009; Beavis, O'Mara, and McNeice, 2012). In this model for games and literacy, the nature of games is both understood as text and action; namely 'gaming literacy' includes the following:

1. 'textual literacy - the 'new literacies' associated with digital iterations of 'reading' (or playing) and 'writing' (or producing) in combination and in multimodal forms (e.g., New London Group, 1996); and

2. 'literacies' specifically linked to the action-based processes of digital gameplay (e.g., Atkins, 2006; Galloway, 2006).

(Apperley and Beavis 2013, 2)

In this model for games and literacy, the primary concern centres on games as part of the expanded repertoire of texts and how games can be brought into the curriculum for study. However, this model also addresses the importance of uncovering the constellation of literacy practices involved in digital gameplay. Building on a view of literacy as a socially situated practice in work on new media (Barton, Hamilton, and Ivanič, 2000; Gee, 2004; Lankshear \& Knobel, 2006), the model provides two layers - or lenses - for analysing how gamers make meaning out of playing games. First, gamers perform physical actions in a specific social context, as illustrated with the first excerpt in the present article. Second, a textual approach provides 'a mode of connecting games, and the actions players take within them, to the wider world' (Apperley and Beavis, 2013). These two layers point to the fact that game literacy is socioculturally situated. As pointed out by Apperley and Beavis (Apperley and Beavis, 2013, 5), 'The games-as-text layer also fleshes out a spectrum of literacy and learning outcomes that are intimately related to context' (5). 
By using these two lenses as a point of departure and using a sociocultural perspective on learning and literacy, we want to understand how young people - on their own and within various contexts - draw upon their experience as gamers. The sociocultural theories of learning and literacy emphasise that learning should be analysed and facilitated as situated, contextualised, authentic and problem based (Gee, 2004; Lave and Wenger, 1991; Potter and McDougall, 2017; Sawyer, 2006; Wertsch, 1991). Learning is both about enculturalisation that is, individuals are socialised into specific ways of using cultural tools, such as language, discourse and material resources - but learning is also about the individual's active and unique interpretation of activities and meanings within the practices and his or her opportunities to change the dominating patterns of participation. Here, learning is seen as a dialogic process of agency and structure. According to Paavola and Hakkarainen (2005), 'learning is seen as a process of becoming a member of a community and acquiring the skills to communicate and act according to its socially negotiated norms' (538). Therefore, a sociocultural perspective of literacy practices builds on the assumption that literacy in games and knowledge related to particular games is learnt in a community of gamers (Hayes and Duncan, 2012; Pellicone and Ahn, 2015).

In our analysis, we understand Emil's participation in FIFA as his actions in various contexts. Based on interviews and 'mediographies', we make an ethnographic account on how he has become a member of a community of FIFA gamers. This point of departure refers to his gameplay as action and his understanding of design and the various contexts for gameplay. In our analysis of Emil's work as a reviewer and on a task he completed for school, we reveal Emil's knowledge about the game and the world around the game, which is soccer in general. 
The data are derived from a 3-year ethnographic study involving students (aged 13-16) from two lower secondary schools: Vestlia and Sørlia (pseudonyms). From the observations (field notes and video-data), questionnaires and group interviews, we identified that some students enjoyed gaming more than others. Specifically, in the current context, the FIFA-gang had been playing FIFA over an extended period of time before we began the 3-year ethnography.

During the years of fieldwork, we collected different types of data that became relevant for describing and analysing how Emil and the other members of the FIFA-gang participated in literacy practices. We carried out ethnographic interviews (Snodgrass 2016; Spradley 2016), recorded sessions of game play at the participants' homes and collected video data of classroom interactions. In line with Hine $(2000,2015)$, we worked with the research subjects across various contexts of their lives to understand how their online and offline practices were being constructed alongside one another. This way of understanding the learners builds on studies of the digital, a subject which lies within an ethnographic tradition (cf Boellstorff, 2006, 2012; Hampton, 2017; Horst and Miller, 2012). In the current ethnographic work on games and literacy, we build on the idea of following the learner. This methodology has been developed in several projects over the last decade (Erstad and Gilje, 2014; Gilje and Erstad, 2016; Sefton-Green, 2016; Sefton-Green and Erstad, 2017). Interestdriven trajectories of participation demonstrate how an individual's use of knowledge and skills from a range of different contexts provide opportunities to the individual to perform his or her agency as a gamer, in this case, as one who is particularly interested in soccer.

By identifying and following the FIFA-gang, data were collected over the 3-year period to understand how the members of the FIFA-gang constructed meaning from their gameplay in diverse cultural and social contexts. Consequently, we draw on a variety of sources and data in the current article. First 'mediographies', or what Mitgutsch termed 'players biographies' (2011), were collected. These mediographies were made by drawing on 
a timeline all the different media and game experiences the pupils could remember from early age to present time (end of grade 10). In the analysis of the mediographies, a certain pattern became evident: A large number of the boys at both schools had written different versions of the FIFA game on their timeline. To illustrate the artefact used as part of the method here and the ways in which these timelines were annotated, two typical male mediographies of FIFA players are presented in Figures 1 and 2.

Insert Figures 1 and 2 - here

As shown in these mediographies, games and game consoles are important for the boys. The mediographies reveal how playing FIFA had become an integrated part of Emil's life from an early age. As we can see, Emil reported on every new version of the FIFA game since FIFA 2006, which launched when Emil was 7 years old.

Although these data give an overview of the male gaming culture that exists in lower secondary school, the data do not give any information about the practice of playing FIFA. So where do these sessions with 'experienced' FIFA players take place, and how do the participants make meaning of these sessions? These overviews of engagement in diverse games created by students provide insight into what kind of games the studied generation, all born in the year 1999, had been playing since they first began. Together with media diaries (Richardson and Hjorth, 2017) and interviews, ${ }^{1}$ the first part of the analysis provides an understanding of the learning trajectory of becoming a FIFA video game player. This first part of the analysis deepens our understanding of the quality and distinctiveness of players'

\footnotetext{
${ }^{1}$ Ethnographic interviews with the members of the FIFA-gang were conducted online, as well as face-to-face, to explore the affinity groups and online sites that mattered to these young people.
} 
experiences throughout their lives, in particular during the studied years at lower secondary. The corpus is shown in Table 1, which gives an overview of the different types of data and their means of analysis in the study.

\begin{tabular}{lll}
\hline Data Source & Use in the Study & Means of analysis \\
\hline $\begin{array}{l}\text { Interviews at school, at home } \\
\text { and online (Skype/Camtasia) }\end{array}$ & $\begin{array}{l}\text { Enabling an understanding of } \\
\text { Emil's interest and } \\
\text { engagement in FIFA }\end{array}$ & $\begin{array}{l}\text { Analysis of student } \\
\text { perspectives of game-related } \\
\text { literacy practices }\end{array}$ \\
$\begin{array}{l}\text { Screenshots of gaming } \\
\text { activities and videos on }\end{array}$ & $\begin{array}{l}\text { Enabling a detailed } \\
\text { YouTube }\end{array}$ & $\begin{array}{l}\text { Visual analysis of how } \\
\text { related artefacts }\end{array}$ \\
$\begin{array}{l}\text { Video and audio recordings and objects were } \\
\text { of collaborative work in } \\
\text { game-related practices and } \\
\text { projects at school }\end{array}$ & $\begin{array}{l}\text { Enabling a detailed } \\
\text { understanding of how the } \\
\text { students demonstrate their }\end{array}$ & $\begin{array}{l}\text { Ethnographic accounts of } \\
\text { social interaction and talks in } \\
\text { diverse settings. }\end{array}$ \\
\hline
\end{tabular}

Table 1. Core data sources (primary and secondary) and their use in the study.

The interviews at the participants' homes and the screenshots of their gaming activities provided knowledge of how the gamers participated in gameplay over time. Although other gamers participated in these gaming practices, we did not obtain primary data from them.

To study how literacy practices are developed around the FIFA video game, we focus on one particular student. According to Yin (2006), 'compared to other methods, the strength of the case study method is its ability to examine, in-depth, a "case" within its "real-life" context' (111). The strength of focusing on one student is that we can examine in-depth how one young boy engages in different activities related to the FIFA video game, thus showing substantial meaning about the activities that happen in real life. Of course, we cannot infer from this analysis that all players of sports games participate in the same way and in the same practices, but we believe that by discussing our findings in relation to other relevant studies, we can shed light on a phenomenon that is part of a shared social world among many young people in contemporary societies. 


\section{Findings}

For many boys and young adults, FIFA is the most popular game, and many spend a considerable number of hours during their leisure time and weekend nights playing this game (Medietilsynet 2016; Stein et al. 2013). The interviews revealed an interest in FIFA as a social experience (Markovits and Green, 2017; Mitgutsch, 2011, 2013), and many of the participants described it in the following way:

Boy:
Interviewer: $\quad$ So, you have several screens.
Boy:
It depends on how many of us there are.
Interviewer: $\quad$ But it happens that you are carrying screens from one house to another?
Boys: $\quad$ Yes, and it depends on how many we are together, playing. (...) from two to

$\quad$ four-five. It also depends on how many we are allowed to have in one home

[living room]

This social experience of being FIFA video game players builds upon years of playing the game, which is true for most boys in the current study. For most of the boys, their playing started between 2007 and 2010, when they got their first PlayStation 2 or PlayStation 3 consoles; as one of the boys stated 'and when we bought [PlayStation3] and stuff, we got really into it and it last for a long time, but then it can be many weeks when we are not that much into it'. More often than these special events, FIFA is played just after soccer practice, as one boy explained: 'the saying is: "okay, we are finished with the training, now let's go home and eat and play FIFA"' (Interview, October 2015). This relationship between playing FIFA and playing soccer in real life relates to how an understanding of a game is associated with activities enacted in other contexts. As two of the boys explained in an interview: 
Boy 1: $\quad$ The coach tells us to stop thinking about playing FIFA [in real life at the field].

Boy 2: $\quad$ Because sometimes you enter the field and think you can do like you do in the sports game FIFA, and then you try to play advanced and to shoot a brass kick in the upper crossing of the goal

Interviewer: And it doesn't work

Boy 1 and 2: Not at all

Boy 1: $\quad$ So many of our mates are told that they should not start a match with a FIFA philosophy [on their mind]

This snippet of conversation relates to how FIFA as action mirrors the boys' experiences with soccer on the field. Looking at FIFA gaming as a social experience as a whole, it differs from other kinds of gaming activities by being a social event, sometimes planned and sometimes taking place after their soccer practice. Moreover, FIFA blends into their gameplay in real life. In this way, we might argue that playing FIFA also impacts how they play soccer on the field.

These two snippets of conversation elaborate on the game play in the introduction of this article. Together, they illustrate how FIFA is played, but also how the members of the FIFAgang develop specific knowledge about FIFA as text when referring to specific qualities that the game's avatars display. In the following analysis that uses Emil as the focus, we emphasise how learning and literacy practices are elaborated upon. In doing so, we are bringing a textual approach into the analysis to connect the literacy practices in Emil's FIFA play with the 'wider world' (Apperley and Beavis, 2013, 5). 


\section{1: Knowledge about FIFA and the world around FIFA}

As illustrated with the mediography above, Emil is one of many boys who play FIFA, ${ }^{2}$ and he has played every new version of the game since he was 7 years old. Because each new version of FIFA aims at making the computer game more authentic, providing more detailed information and footage of each individual football player in the UEFA Champions League, the video game has become a more realistic simulation of soccer (Sicart 2013). ${ }^{3}$ Emil has also played soccer since he was 7 years old, and every day, he has kept himself updated on news about his favourite soccer team, Viking (a Norwegian team based in Stavanger, which is located on the west coast of Norway). At the end of the ninth grade, Emil signed up to be a reviewer for EA sports. Reviewers, analysts and photo editors, among others, are positions that can be applied for on FIFA's website. ${ }^{4}$ Emil discovered that EA Sports needed new reviewers and completed an application in which he had to write about himself. 'Fortunately', he said, 'I did not have to tell my age, only that I consider myself as above legit working age. And then I had to write how often I expected to work on the tasks' (Interview, October 2015). A data reviewer in FIFA improves the accuracy of the skills and competencies of the players, and Emil had worked his way up to be a top-level data reviewer:

Emil: $\quad$ As a reviewer, I am on top [the highest], but ... I have of course someone who is above me, and they can then [edit]; my job is to review, for instance, if I press a player then, 'N' [name]...

\footnotetext{
${ }^{2}$ During our fieldwork, FIFA 15, a new version of the game, was launched (25 September 2014). This is the game the students refer to in the interviews and play in the interactional video data. Almost every boy had access to FIFA 15 on PlayStation 4 (which launched November 2013).

${ }^{3}$ Sicart (2013) argued that the rules, tactics and stars in FIFA are central aspects of the video game, and the practice of engaging and discussing stars is 'a step in fandom for which computing simulations are offering new degrees of depth and engagement to our fantasies' (2013, 43). In FIFA 15, it is striking to see how the game simulates both the soccer match and the media broadcasting of the event. 'In the FIFA franchise, as in most products under the EA sports label, the drive is to make the games even closer to the actual game, that is, to make the computer game converge with the sport' (Sicart 2013, 33).

${ }^{4}$ http://fifa-talentscout.ea.com/. Available 10 June 2017.
} 
Interviewer: This is the player's real name?

Emil: $\quad$ Yes, that is his real name.

Interviewer: $\quad \ldots$ a Norwegian player.

Emil: $\quad$ Yes, I have access to all the players in the top [Norwegian] league.

Interview, June 2015.

In this excerpt, Emil performed his knowledge about the game, as well as his knowledge about the club Viking, as he wrote and edited the different skills for a specific player. This literacy practice included an understanding of how EA sports developed a game he had been playing for almost ten years. And more specifically, his reviewer role gave Emil challenges regarding writing in a foreign language and understanding the specific online tool he was required to use. ${ }^{5}$ His job gave him access to adjust players in the league on a scale from 0 100. Recalling the second excerpt in the beginning of the present article, which showed how one specific player is 'programmed' in the game, we have some idea of how these skills are commented on and discussed in an in-game setting. Throughout his participation, Emil performed his expert reviewer role for the team Viking and suggested that the FIFA developers make this team even more 'realistic' in the next version of the game - FIFA 2017. His comments and suggestions may have led to a change in the real game, as he explained:

Emil: $\quad$... say this is how it's going to look like FIFA 16. [but] I cannot change anything. My job is to go investigate what's called 'feedback' - see here Interviewer: Yes?

Boy: I wrote: XXX should have a better sprint and overhead kick. [These suggestions] are mine, and if they accept it ...

\footnotetext{
${ }^{5}$ Reviewers might be promoted to data editors, which is considered a 'fantastic place to start for anyone who has wanted to be a part of the EA SPORTS FIFA Team, regardless of where you live in the world'. (https://www.easports.com/fifa/news/2014/fifa-ea-talent-scout-team)
} 
Interviewer: So you refer to the knowledge you have about the players in real life, and say that this is incorrectly in regard to how the player is programmed [in FIFA]

Emil: $\quad$ That's right. And in order to give them an evidence, I need to quote a source. In this particular case, I gave them [EA sports) this video (points at the screen). And then, if they think it's okay, they write something like: 'great ... thanks' and then the actual player will be a better player [in FIFA]. So that's my job. I'm not allowed to change myself, but I can come up with suggestions for those who are 'over me' in the hierarchy. So that's my job!

Interview, June 2015

Two topics are interesting in this excerpt. First, Emil had to research each player individually and find evidence for his suggestions about changing the player's skills in FIFA. This literacy practice implies the possibility of changing the game and providing information to build avatars (the specific soccer player on a specific team) for the next version of the game. The literacies involved here include being able to research a specific topic, building a convincing argument for it, and transferring knowledge from one source to another in a critical way. Presented in this way, we might think that the process of working with the game mirrors an academic way of thinking about how to work with knowledge in a specific field. Thinking of FIFA as a text, Emil needs to know how the game is structured and programmed, indicating that he is demonstrating knowledge about the game and the world around the game (Beavis \& Apperley, 2012). Bringing the two layers together in a model for games and literacy, it can be seen that Emil builds upon his understanding of the design in the game, which is based upon his gameplay. And this knowledge about the game gives him an understanding of the 'narrative structures and features' (Apperley and Beavis, 2013, 20) in FIFA. 
The tool provided for reviewing and adjusting the players provide a context where Emil's specific team - Viking - and knowledge of this team becomes valuable. But to suggest different values of the avatars Emil must also have 'tool literacies' for solving the tasks he is given as a reviewer in EA sports:
Emil: $\quad$ If I press here, for instance; 'Viking'.
Interviewer: So they categorise you as a reviewer at level 5?
Emil: $\quad$ Yes, but I started at level 1, so I have worked my way up to level 5.
Interviewer: How many levels are there?
Emil: $\quad$ As a reviewer, I am on top [the highest], but ... I have of course someone who is above me, and they can then [edit]; my job is to review, for instance, if I press a player then, ' $\mathrm{N}$ ' [name]...
Interviewer: This is the player's real name?
Emil: $\quad$ Yes, that is his real name.
Interviewer: $\quad \ldots$ a Norwegian player.
Emil: $\quad$ Yes, I have access to all the players in the top [Norwegian] league.

By being a member of the community of reviewers, Emil became more than a player of FIFA - he positioned himself as a member of a larger community of reviewers in FIFA.

We might suggest that his utterance, 'I have of course someone who is above me, and they can then [edit]; my job is to review...', shows that his specific field for reviewing is based on his expert knowledge about Viking, a team he and his father have been following for many years. The information that he has acquired as fan of the team has given him the kind of knowledge that makes it possible for him to suggest which of the players' skills should be adjusted. 
Using the specific tools provided by EA Sports, Emil became a participant in a collaborative practice where he could use his proficient knowledge about a specific Norwegian team. This expert knowledge was needed as a reviewer in the specific literacy practice, and it came from Emil's interests in a specific game and from his interest in soccer. Emil used the information from this community to search the site for reviewers for specific knowledge of how to do things and looked at what others posted. Moreover, his knowledge about soccer had to be used within the community of reviewers in Norway. In this community, Emil learned how to create specific knowledge in a template, and as he participated in the community of reviewers, he had to write everything in English.

\subsection{Learning as a soccer fan and game player in the context of school}

As part of an assignment for school, Emil assumed the role of a sports journalist and conducted an interview with the coach of a local football team early in the morning ( $8 \mathrm{am})$. This interview was neatly planned because it was part of a school project where the students made a newspaper in school, covering different topics related to sports. The first author took the role of participant observer in this event and drove Emil from the school to the local stadium, which is nine kilometres away. As with his engagement as a reviewer in FIFA, Emil had done substantial research before interviewing the trainer, as seen in the following:

Emil: For instance, Leander has performed well this year. He is one of those players that can help the team one more season. Do you think he will stay if you don't succeed in moving up one division?

Trainer: He is probably one of those players who is leaving. He is a well-known player in many of the teams in the elite division. So I think he will leave.

Emil: $\quad$ Ok 
In this conversation, Emil's interest in the local team surfaced in a slightly different way than in his work as a reviewer for FIFA. In the literacy practice related to this interview, reading the local newspaper and related sites on the Internet gave him the relevant background he needed to conduct the interview. Moreover, Emil had to understand the genre of doing an interview, which includes taking notes and asking new and relevant questions. Later in the same day and back at school, Emil worked on the task of creating the newspaper for 4 hours to complete it before the deadline; interestingly, he was very concerned about making the newspaper look serious. Thus, he constantly argued with his group members regarding what the paper should look like. In several events, which are recorded in the video data, Emil took the role of being a serious editor, while his group members made off-task suggestions about the design and name of the newspaper. In his work on the computer, he had to search for more information on the Internet, write and edit in Word and discuss the content of the interview with the other members of his group.

\section{Insert figure 3 here: Working with their newspaper in school}

More specifically, Emil drew upon his knowledge of specific players on the local team and positioned himself as an eager journalist and editor of the paper. In many ways, this kind of knowledge resembles the kind involved in the literacy Emil practiced in his role as a reviewer for EA sports. However, the school project took place in the course of a day, and the ways in which he was involved in the project were different compared with his role as a reviewer. In the discussion, we focus on how literacy related to FIFA can be demonstrated in the two outof-school practices compared with this school project. 


\section{Discussion}

From a global perspective, FIFA has become the most popular video game and has the longest series of new versions. Considering these numbers, the FIFA culture among the studied boys mirrored international and national survey data on FIFA (Markovits and Green, 2017; Medietilsynet, 2016). In our analysis, we have been concerned with how Emil participated in literacy practices related to the game and to soccer in general over time and across contexts. The analysis builds on the two layers: games-as-action and games-as-text (Beavis and Apperley, 2012). In particular, we have tried to illuminate how Emil's gameplay as part of the FIFA-gang extends into other contexts.

When analysing Emil's literacy practices as a reviewer, we have unpacked a complex form of specific knowledge related to FIFA itself, but also a lifelong experience of being a fan of a specific team. In doing this, we suggest that the model for games and literacy introduced by Beavis and Apperley (2012) can be used as a point of departure for understanding diverse literacy practices related to knowledge about FIFA in particular and soccer in general. In this final discussion, we want to make two points in relation to our findings.

First, the knowledge and interest in Emil's favourite team, Viking, became embedded in the game when he signed up for being a reviewer. Consequently, he could use his knowledge to become a 'local' expert in the global community of EA reviewers. At the age of 16, 2 years before one can legally contribute as a reviewer, he managed to transform his knowledge about Viking players into a demonstrable improvement in an international, commercial game. This kind of work did not give him any kind of salary, just the fame of being a reviewer in a global online community. By doing this, he was 'stepping up' and 'a step in fandom for which computing simulations are offering new degrees of depth and engagement to our fantasies' 
(Sicart 2013, 43). In a broader perspective, this illustrate how gamers can perform literacy and enact agency in practices that are meaningful to them as young people in contemporary societies.

Second, the project of making a newspaper, which occurred in the context of school, allowed Emil to use his specific knowledge about soccer, which had been obtained by reading newspapers and online articles. The literacy practices involved in the school project can be related to how he developed knowledge about the team Viking. Even though the tasks were different, doing an interview in a school project and 'programming' an avatar (a specific player) for Viking, they both draw upon the same type of interest-driven participation conducted by Emil. For the school project, his local knowledge had value for a specific school task. As the excerpt in 5.2 indicates, his motives and interest in this work made him eager in getting the work done at school. In a broader perspective, this illustrates how gamers might perform literacy across disparate contexts and can make connections between these contexts in activities that often are quite different in nature.

By following Emil and his interest-driven trajectories in diverse, but interconnected, contexts, we have illustrated how he drew on material resources and used cultural tools in literacy practices in and out of school. By using two lenses on games (games-as-action and games-astext) as a point of departure, we have illustrated how Emil made use of knowledge about the game and the world around the game in other contexts.

Being an exploratory study that followed young learners for over 3 years in lower high school (ages 14-16), the ethnographic data allowed for an analysis of literacy practices in the classroom that could be related to the wide range of game-related literacy practices we discovered in the students' out-of-school practices (cf Gilje and Erstad, 2014). Consequently, 
the current article adds one perspective to how we can understand learning outside of formal schooling because it has looked at a particular practice of gameplay, namely at FIFA gamers in their childhood and early teenage years. We can understand these practices of participating in digital culture not simply from a learning perspective, but also from a view of understanding new forms of civil and civic society (Jenkins, Shresthova, and GamberThompson 2016; Jenkins et al. 2007).

Emil's story may show us something about what technologies offer us: 'ample possibilities for purposeful integration of tools for social connection and knowledge co-creation and for linking classroom, community, and home' (Kumpulainen and Sefton-Green, 2014, 9). By drawing on a learning lives perspective, we propose more focus on learners' agency in the model for games and literacy, which originally was developed for teaching English and literacy curriculum. Hopefully, our ethnographic account can give teachers insight into what kinds of literacy practices students engage in when it comes to learning and literacy in a wider world around video games - not only in the game as a gamer in interaction with the software. Teasing out this knowledge as a background for making projects about games even more interesting in school is challenging, but it may be one fruitful way of engaging students with their agency as gamers across different contexts.

\section{Funding and acknowledgements}

This research was funded by the Norwegian Research Council (FINNUT). XXX project is a collaborative project, and we appreciate all the comments and suggestions received from our colleagues.

\section{Declaration of Conflicting Interests}


Learning, media and technology, revised article, August, 2018

The authors declare no potential conflicts of interest with respect to the research, authorship and publication of this article. 


\section{References}

Author 1 and $x x$

$\mathrm{Xx}$ and author 1

Author 2. 2012

Apperley, T., and Beavis, C. 2013. A Model for Critical Games Literacy. E-learning and Digital Media, 10(1), 1-12.

Barton, D., Hamilton, M., and Ivanič, R. 2000. Situated literacies: Reading and writing in context. London. Routledge.

Beavis, C., and Apperley, T. 2012. A model for games and literacy. Digital games: Literacy in action, 12-23.

Beavis, C., Apperley, T., Bradford, C., O'Mara, J., and Walsh, C. 2009. Literacy in the digital age: Learning from computer games. English in Education, 43(2), 162-175.

Beavis, C., and O'Mara, J. 2010. Computer games-pushing at the boundaries of literacy. Australian Journal of Language and Literacy, The, 33(1), 65.

Beavis, C., O'Mara, J., \& McNeice, L. 2012. Digital games: Literacy in action: Wakefield Press.

Boellstorff, T. (2006). A Ludicrous Discipline? Ethnography and Game Studies. Games and Culture, 1(1), 29-35. doi:10.1177/1555412005281620

Boellstorff, T. 2012. Ethnography and virtual worlds: a handbook of method. Princeton, N.Y.: Princeton University Press.

Del Castillo, H., Herrero, D., Monjelat, N., García, A., and Checa, M. 2011. Identity \& performance: developing innovative educational settings through sport video games. Paper presented at the Proceedings of ICERI 2011 Conference. Madrid. November 2011.

Gee, J. P. 2003. What video games have to teach us about learning and literacy. New York: Palgrave Macmillan.

Gee, J. P. 2004. Situated language and learning: a critique of traditional schooling. London: Routledge.

Gee, J. P. 2007. Good video games + good learning: collected essays on video games, learning, and literacy. New York: P. Lang.

Green, B. 1988. Subject-Specific Literacy and School Learning: A Focus on Writing. Australian Journal of Education, 32(2), 156-179. doi:10.1177/000494418803200203

Green, B. 1999. The new literacy challenge. Literacy Learning: secondary thoughts, 7(1), 36-46.

Hampton, K. N. 2017. Studying the Digital: Directions and Challenges for Digital Methods. Annual Review of Sociology, 43(1), 167-188..

Hanghøj, T., Hautopp, H., Jessen, C., Denning, R. C., \& Busch, I. 2014. Redesigning and reframing educational scenarios for Minecraft within mother tongue education. Paper presented at the Proceedings of 8th European Conference on Games Based Learning (ECGBL2014).

Hayes, E. R. 2013. A new look at girls, gaming and literacies. In: Guzzetti B. J. and Bean T. W., (Eds.) Adolescent literacies and the gendered self.(Re) constructing identities through multimodal literacy practices, 101-108.

Hayes, E. R., and Duncan, S. C. 2012. Learning in Video Game Affinity Spaces. New Literacies and Digital Epistemologies. Volume 51. New York: Peter Lang Publishing.

Horst, H. A., \& Miller, D. 2012. Digital anthropology. London: Berg.

Ito, M., Baumer, S., Bittanti, M., Boyd, D., Cody, R., Herr, B., \& Tripp, L. (2009). Hanging out, messing around, geeking out: Living and learning with new media. Cambridge: MIT Press.

Kumpulainen, K., \& Sefton-Green, J. 2014. What Is Connected Learning and How to Research It? International Journal of Learning and Media 4(2), 7-18. 
Lankshear, C., and Knobel, M. 2006. New literacies: Everyday practices and classroom learning. Maidenhead: Open Univ Press.

Lave, J., \& Wenger, E. 1991. Situated learning: legitimate peripheral participation. Cambridge: Cambridge University Press.

Leander, K., Phillips, N., and Taylor, K. H. 2010. The Changing Social Spaces of Learning: Mapping New Mobilities. Review of Research in Education, 34, 329-394.

Leander, K. M., and Jason, F. L. 2006. Literacy Networks: Following the Circulation of Texts, Bodies, and Objects in the Schooling and Online Gaming of One Youth. Cognition and Instruction, 24(3), 291-340. doi:10.2307/27739837

Markovits, A. S., and Green, A. I. 2017. FIFA, the video game: a major vehicle for soccer's popularization in the United States. Sport in Society, 20(5-6), 716-734. doi:10.1080/17430437.2016.1158473

Medietilsynet, N. M. A. 2016. Barn \& Medier 2016. 9-16 åringers bruk og opplevelser av medier. Retrieved from Fredrikstad: http://www.medietilsynet.no/globalassets/publikasjoner/barnog-medier-undersokelser/2016 barnogmedier.pdf Accessed 14 August 2018.

Mitgutsch, K. 2011. Playful learning experiences: meaningful learning patterns in players' biographies. International Journal of Gaming and Computer-Mediated Simulations (IJGCMS), $3(3), 54-68$.

Mitgutsch, K. 2013. Why sports videogames matter to their players - Exploring meaningful experiences in playographies. In K. Mitgutsch, A. Stein, \& M. Consalvo (Eds.), Sports videogames (pp. 253-277). New York: Routledge.

Nash, P., and Shaffer, D. W. 2011. Mentor modeling: The internalization of modeled professional thinking in an epistemic game. Journal of Computer Assisted Learning, 27(2), 173-189.

Pellicone, A., and Ahn, J. 2015. Building Worlds: A Connective Ethnography of Play in Minecraft. Games and Culture. 13(5) doi:10.1177/1555412015622345

Potter, J., and McDougall, J. 2017. Digital Media, Culture \& Education - Theorising Third Space Literacies. London: Palgrave Macmillan.

Richardson, I., and Hjorth, L. 2017. Mobile media, domestic play and haptic ethnography. New media \& society. 19(10) doi:10.1177/1461444817717516

Sawyer, R. K. 2006. The Cambridge handbook of the learning sciences (Vol. 2): Cambridge University Press New York.

Sefton-Green, J. 2016. Representing learning lives: what does it mean to map learning journeys? International Journal of Educational Research. 111-118. doi:http://dx.doi.org/10.1016/i.ijer.2016.05.003

Sefton-Green, J., and Erstad, O. (2017). Researching 'learning lives' - a new agenda for learning, media and technology. Learning, Media and technology, 42(2), 246-250. doi:10.1080/17439884.2016.1170034

Sicart, M. (2013). A tale of two games. In M. Consalvo, K. Mitgutsch, \& A. Stein (Eds.), Sports Videogames (pp. 32-49). New York: Routledge.

Stein, A., Mitgutsch, K., \& Consalvo, M. 2013. Who are sports gamers? A large scale study of sports video game players. Convergence, 19(3), 345-363.

Steinkuehler, C., and King, E. 2009) Digital literacies for the disengaged: creating after school contexts to support boys' game-based literacy skills. On the Horizon, 17(1), 47-59.

Steinkuehler, C. A. 2006. Massively multiplayer online video gaming as participation in a discourse. Mind, Culture, and Activity, 13(1), 38-52.

Stevens, R., Satwicz, T., and McCarthy, L. 2008. In-game, in-room, in-world: Reconnecting video game play to the rest of kids' lives. In K. Salen (Ed.), The ecology of games: Connecting youth, games, and learning. Cambridge, Mass.: MIT Press.

Wertsch, J. V. 1991. Voices of the mind: a sociocultural approach to mediated action. Cambridge, Mass.: Harvard University Press.

Williamson, B., and Facer, K. 2004. More than 'just a game': The implications for schools of children's computer games communities. Education, Communication \& Information, 4(2/3), 255-270. 
Learning, media and technology, revised article, August, 2018

$\emptyset$ ygardslia, K. 2018. 'But this isn't school': exploring tensions in the intersection between school and leisure activities in classroom game design. Learning, Media and Technology, 43(1), 85-100. 